\title{
Do not resuscitate orders: practice vs. medical record notes
}

\author{
Ordens de não ressuscitar: prática versus registro em prontuário
}

\section{Luiz Guilherme Araujo Florence ${ }^{1}$, Cláudio Schvartsman², Eduardo Juan Troster ${ }^{3}$, Pilar Lecussan Gutierrez ${ }^{4}$, Amélia Gorete Reis ${ }^{5}$}

\section{Resumo}

Objetivo: Avaliar a veracidade do registro do óbito de pacientes pediátricos de um hospital terciário e comparar esse dado com o de um estudo anterior.

Métodos: $O$ registro do óbito apresentado nos prontuários dos pacientes não ressuscitados entre os anos de 1999 e 2001 foi confrontado com o ato médico realizado durante as paradas cardiorrespiratórias, cuja descrição se deu através da padronização Utstein. Esse resultado foi comparado (através do teste de qui-quadrado, com proporções de concordância) com os resultados de um estudo anterior, que havia encontrado uma discrepância expressiva entre $o$ ato médico e o registro de óbito em prontuário.

Resultados: Observamos uma concordância entre a prática médica e o registro no prontuário em $86,5 \%$ dos casos. No estudo anterior essa taxa foi de apenas $27,5 \%$.

Conclusões: Houve uma redução significativa na discrepância entre o ato médico e o registro de óbito no prontuário.

J Pediatr (Rio J). 2009;85(4):369-372: Ordens de não ressuscitar, ética, ressuscitação cardiopulmonar.

\begin{abstract}
Objective: To evaluate the accuracy of pediatric patients' death records of a tertiary care center, comparing these records with data from a previous study.

Methods: Death records entered on the medical charts of nonresuscitated patients between 1999 and 2001 were compared with the medical procedure during cardiac arrest, which was described based on the Utstein-style guidelines. Our results were compared (using the chisquare test for equality of distributions) with the results of a previous study, which revealed a significant discrepancy between the medical procedure and the death record entered on the medical chart.

Results: The data analysis revealed agreement between the medical procedure and the medical record notes in $86.5 \%$ of the cases. The agreement rate in the previous study was only $27.5 \%$.

Conclusions: There was a significant reduction of discrepancy between the medical procedure during a cardiac arrest and the death record entered on the medical chart.

J Pediatr (Rio J). 2009;85(4):369-372: Do-not-resuscitate orders, ethics, cardiopulmonary resuscitation.
\end{abstract}

\section{Introdução}

O termo ressuscitação cardiopulmonar ( $R C P$ ) é usado como síntese de uma série de procedimentos que visam evitar a morte de um paciente com comprometimento grave de suas funções vitais ${ }^{1}$. Geralmente são aplicados em situações

de rápida deterioração funcional, mas isso não implica que os pacientes com comprometimento prévio de seu estado de saúde deixem de ser submetidos aos procedimentos de RCP. Nessas situações, o prognóstico torna-se incerto ${ }^{1,2}$, e

1. Médico colaborador, Pronto-Socorro, Instituto da Criança, Hospital de Clínicas, Faculdade de Medicina, Universidade de São Paulo (USP), São Paulo, SP.

2. Chefe, Pronto-Socorro, Instituto da Criança, Hospital de Clínicas, Faculdade de Medicina, USP, São Paulo, SP

3. Professor livre-docente, Departamento de Pediatria, Faculdade de Medicina, USP, São Paulo, SP.

4. Membro, Comissão de Bioética, Hospital de Clínicas, Faculdade de Medicina, USP, São Paulo, SP.

5. Doutora, Pediatria, Faculdade de Medicina, USP, São Paulo, SP.

Este estudo foi realizado na Faculdade de Medicina, Universidade de São Paulo (USP), São Paulo, SP.

Não foram declarados conflitos de interesse associados à publicação deste artigo.

Como citar este artigo: Florence LG, Schvartsman C, Troster EJ, Gutierrez PL, Reis AG. Do not resuscitate orders: practice vs. medical record notes. J Pediatr (Rio J). 2009;85(4):369-372.

Artigo submetido em 15.07.08, aceito em 04.03.09

doi:10.2223/JPED.1906 
a equipe de saúde vivencia um dilema moral e ético quanto a qual seria a decisão mais apropriada em prol do paciente e de sua família.

Diante desse contexto, pesquisadores têm se preocupado cada vez mais em determinar com precisão em quais situações deve ser indicado o uso da RCP. Em 1976, publicou-se a primeira normatização de ordem de não ressuscitação na literatura médica estrangeira ${ }^{3}$. Intensos debates se estabeleceram a partir de então, havendo um progresso substancial na restrição da tendência de aplicação universal de RCP em pacientes sem prognóstico ${ }^{3}$.

A ordem de não ressuscitar pacientes terminais é uma conduta amparada moral e eticamente, porém ela ainda encontra alguns entraves. No Brasil, essa conduta ainda não está institucionalizada e não tem aceitação legal unânime e pacífica ${ }^{4}$. Diante disso, os médicos costumam ter receios quanto a não realizar manobras de ressuscitação em pacientes terminais, temendo sofrer algum tipo de penalidade legal. Para agravar a questão, ainda temos poucos dados nacionais em relação à implementação de ordens formais de não ressuscitação e restrição de RCP.

Torreão et al. ${ }^{4}$ avaliaram um indicador indireto que pôde ajudar na dimensão da dificuldade da equipe de saúde em lidar com a morte. A partir do estilo Utstein ${ }^{5}$, foram registrados os casos de paradas cardiorrespiratórias (PCR) em um hospital pediátrico de nível terciário, durante 1 ano. Os pesquisadores verificaram $176 \mathrm{PCR}$, dentre as quais 47 indivíduos não foram ressuscitados. Desses casos, foram confrontados os registros de PCR dos pesquisadores com os prontuários preenchidos pelos médicos que assistiram ao óbito; em 11 casos (27,5\%), a descrição no prontuário era "constatado o óbito", e nos outros 29 (72,5\%) constava "feitas manobras de ressuscitação sem sucesso". Os autores concluíram que a discrepância encontrada poderia se dever ao receio das consequências legais de tal conduta médica. Esse estudo foi publicado no ano 2000 no Jornal de Pediatria, entretanto a divulgação dos seus resultados ocorreu internamente ao longo do ano de 1999. Diante de tal fato, a Comissão de Bioética do hospital organizou uma série de reuniões com o objetivo de orientar os médicos da instituição na decisão de indicarem ou não as manobras de ressuscitação e para registrarem de forma correta e honesta essa decisão no prontuário.

Sendo assim, o objetivo deste estudo é avaliar, retrospectivamente, a veracidade com que foram registradas as informações referentes ao óbito de pacientes de um hospital terciário pediátrico e, em seguida, avaliar a diferença encontrada na maneira como o prontuário médico passou a ser preenchido após as intervenções do Comitê de Bioética no ano de 1999.

\section{Métodos \\ Local}

O estudo foi realizado no hospital escola pediátrico terciário Instituto da Criança, do Hospital de Clínicas, Faculdade de Medicina, Universidade de São Paulo, São Paulo (SP).

\section{Delineamento}

Após a aprovação do Comitê de Bioética da instituição, um pesquisador analisou os prontuários dos pacientes que sofreram PCR e não foram submetidos às manobras de RCP, no período de 31 de outubro de 1999 a 30 de setembro de 2001. Essa casuística foi resgatada a partir do estudo de Perondi et al. ${ }^{6}$, ensaio clínico tipo coorte, prospectivo, realizado na mesma instituição, onde foram registrados os dados de todos os pacientes que sofreram $P C R$, incluindo os que receberam e os que não receberam manobras de ressuscitação. A forma de registro da PCR seguiu a padronização Utstein ${ }^{5}$, na qual os procedimentos de RCP são coletados de forma prospectiva e sistemática e a presença de RCP é definida através do emprego de compressão torácica.

Além da folha de óbito, foram analisados também o último relato da enfermagem, a última evolução médica e a última prescrição médica. O conteúdo apresentado no prontuário foi confrontado com a ficha do registro de óbito obtida a partir do estudo de Perondi et al. ${ }^{6}$. Seus resultados foram comparados (através do teste de qui-quadrado, com proporções de concordância) com os resultados do estudo de Torreão et al. ${ }^{4}$, que havia encontrado uma discrepância importante entre o ato médico e o registro de óbito em prontuário.

\section{Resultados}

Ocorreram 185 PCR, das quais $118(63,8 \%)$ sofreram manobras de RCP e 67 (36,2\%) não foram submetidas a RCP. A população analisada no presente estudo compreende, então, estas últimas 67 crianças que não foram ressuscitadas. A análise de coerência foi realizada nesses 67 prontuários, porém em 15 deles não havia informações referentes a PCR ou RCP devido a extravio completo ou parcial do prontuário no serviço de arquivo médico.

Houve predominância do sexo feminino, responsável por $55 \%$ dos casos. A mediana de idade foi de 4 anos e 3 meses e a média de 6 anos e 11 meses. O tempo de internação variou de 0 a 45 dias. Em $85 \%$ dos óbitos, havia a presença de um membro da equipe de saúde que atendia o paciente; $70 \%$ estavam sob monitorização cardíaca, $60 \%$ em ventilação mecânica e $51 \%$ faziam uso de drogas vasoativas.

Em relação à causa imediata do óbito, $40 \%$ dos pacientes apresentaram choque séptico, $34,5 \%$ insuficiência respiratória e 4,5\% choque cardiogênico. A doença de base mais encontrada foi a oncológica, com $43 \%$ dos pacientes, seguida de doença hepática em $21 \%$, cardíaca e neurológica em 7,5\%. Em 4,5\% dos pacientes não havia doença de base. O óbito ocorreu em $63 \%$ dos casos na UTI, $16,5 \%$ no pronto-socorro e $15 \%$ na enfermaria.

Havia registro de óbito no prontuário de 52 pacientes não ressuscitados. Em 45 (86,5\%), a referência era "constatado o óbito", e em sete $(13,5 \%)$ havia descrições 
que remetiam a tentativas de ressuscitação sem sucesso. Portanto, a análise dos dados revelou uma concordância entre a prática médica e o registro no prontuário em $86,5 \%$ dos casos, sendo que no estudo anterior essa taxa foi de apenas $27,5 \%(p<0,0000001)$.

\section{Discussão}

O presente estudo demonstrou que houve redução significativa na discrepância entre o ato médico e o registro de óbito no prontuário, fato que aponta para uma mudança no entendimento de como podem ser feitas as intervenções médicas em pacientes no final da vida.

O perfil dos pacientes atendidos na instituição permaneceu o mesmo, não havendo diferenças expressivas em suas características demográficas e epidemiológicas em relação ao estudo de Torreão et al. ${ }^{4}$. Entre os pacientes que não foram ressuscitados, apenas $4,5 \%$ não tinham doença de base, portanto a maioria dos pacientes atendidos em condições críticas e que não foram ressuscitados tinham alguma doença de base, sendo a maioria oncológica (43\%). Eram pacientes graves, dos quais cerca de $63 \%$ foram a óbito na UTI e $60 \%$ estavam em ventilação mecânica. A porcentagem de pacientes que não foram submetidos a RCP encontrada neste estudo $(36,2 \%)$ se assemelha às encontradas em outros serviços de saúde brasileiros, da América Latina e dos EUA ${ }^{7-9}$.

A ordem de não ressuscitar é apenas uma das ações de limitação de suporte de vida (LSV) que pode ser tomada em pacientes terminais, porém ela é a mais comumente adotada em todos os serviços de saúde do mundo7,9. Na pediatria, esse procedimento também se tornou mais comum, principalmente em centros de tratamento paliativo ${ }^{10}$. Alguns autores sugerem que o termo "ordem de não ressuscitar" seja modificado para "permitir uma morte natural (allow natural death)", não sendo assim erroneamente interpretado como um ato de omissão ${ }^{10}$.

É sabido que, nas últimas décadas, foram realizados inúmeros avanços tecnológicos na área de saúde, possibilitando a cura de muitos pacientes que em outra época teriam sucumbido. Concomitantemente, surge a necessidade de refletir sobre o uso apropriado de tais tecnologias, num momento em que se torna indispensável uma relação mais equilibrada entre paciente, família e médico. A ética médica tradicional, baseada no modelo hipocrático, tem forte acento paternalista. Até a primeira metade do século $\mathrm{XX}$, qualquer ato médico era julgado levando-se em conta apenas a moralidade do agente, desconsiderando-se os valores e crenças dos enfermos. Somente a partir da década de 60 , os códigos de ética profissional passaram a reconhecer o doente como agente autônomo ${ }^{11}$.
Podemos interpretar, a partir dos resultados deste estudo, que esses conceitos estão cada vez mais difundidos entre a classe médica. O amparo institucional prestado ao profissional de saúde do hospital escola no qual o estudo foi conduzido permitiu que o médico se sentisse mais confortável em registrar com fidelidade sua prática terapêutica nessas circunstâncias de final da vida. O resultado deste estudo proporcionou a visualização de um movimento positivo em benefício do paciente. Mesmo sem haver leis estabelecidas no Brasil que possam regular a prática médica no fim de vida, torna-se soberana a decisão de não gerar sofrimento sem objetivo ao paciente. Nem por isso convém dar-se por satisfeito com resultados empíricos tão específicos. Para que tal prática benéfica se difunda ainda mais e sobrepuje as condutas inadequadas, são necessárias novas instâncias de regulamentação.

\section{Referências}

1. 2005 American Heart Association Guidelines for Cardiopulmonary Resuscitation and Emergency Cardiovascular Care. Part 3: Overview of CPR. Circulation. 2005;112:IV-12-IV-18. http://circ. ahajournals.org/cgi/content/full/112/24_suppl/IV-12. Acesso: 27/08/2007.

2. American Academy of Pediatrics Committee on Bioethics: Guidelines on foregoing life-sustaining medical treatment. Pediatrics. 1994; 93:532-6.

3. Burns JP, Edwards J, Johnson J, Cassem NH, Truog RD. Do-not-resuscitate order after 25 years. Crit Care Med. 2003;31:1543-50.

4. Torreão LA, Reis AG, Troster EJ, Oselka G. Ressuscitação cardiopulmonar: discrepância entre o procedimento de ressuscitação e o registro no prontuário. J Pediatr (Rio J). $2000 ; 76: 429-33$

5. Reis AG, Nadkarni V, Perondi MB, Grisi S, Berg RA. A prospective investigation into the epidemiology of in-hospital pediatric cardiopulmonary resuscitation using the international Utstein reporting style. Pediatrics. 2002;109:200-9.

6. Perondi MB, Reis AG, Paiva EF, Nadkarni VM, Berg RA. A comparison of high-dose and standard-dose epinephrine in children with cardiac arrest. N Engl J Med. 2004;350:1722-30.

7. Lago PM, Piva J, Kipper D, Garcia PC, Pretto C, Giongo M, et al. Limitação de suporte de vida em três unidades de terapia intensiva pediátrica do sul do Brasil. J Pediatr (Rio J). 2005;81:111-7.

8. Lago PM, Devictor D, Piva JP, Bergounioux J. End-of-life care in children: the Brazilian and the international perspectives. J Pediatr (Rio J). 2007;83(2 Suppl):S109-16.

9. Levetown M, Pollack MM, Cuerdon TT, Ruttimann UE, Glover JJ. Limitations and withdrawals of medical intervention in pediatric critical care. JAMA. 1994;272:1271-5. 
10. Berkowitz I, Morrison W. Do not attempt resuscitation orders in pediatrics. Pediatr Clin North Am. 2007;54:757-71.

11. Brasil, Conselho Federal de Medicina. Resolução CFM No 1.805/2006. Diário Oficial da União Brasília, 28 de novembro de 2006. Seção I:p.169.
Correspondência:

Amélia Gorete Reis

Rua Petrópolis, 250

CEP 01254-030 - São Paulo, SP

Tel.: (11) 3747.3116, (11) 9999.3562

Fax: (11) 3747.3154

E-mail: ameliareis@terra.com.br 